VOCES DEL EQUIPO EDITORIAL

Rev Chil Salud Pública 2014; Vol 18 (3): 294-297

\section{EL TRABAJO Y LA ORGANIZACIÓN EN EL CAMPO DE LA SALUD}

Hugo Spinelu

Director del Instituto de Salud Colectiva Universidad Nacional de Lanús, Argentina
Antes de la revolución industrial del siglo XVIII no existían grandes fábricas. Los artesanos trabajaban solos, en pequeños talleres, realizando sus tareas a mano y empleando herramientas muy sencillas. La aplicación de la energía hidráulica fue crucial para el desarrollo de la revolución industrial, la cual consolidó la fábrica como espacio productivo y entonces el trabajo cambió, se fragmentó. Se dice que mientras Taylor le "sacó el ocio" al trabajador al cronometrar sus movimientos, Ford se lo "sacó a los materiales" con sus líneas de producción. Así, el ritmo pasó a ser impuesto por las máquinas y el propio trabajador devino objeto para la lógica organizacional. ¿Las consecuencias? El ocaso del trabajo artesanal. Chaplin en Tiempos Modernos hace de todo esto un resumen brillante.

Esta apretada síntesis histórica de la evolución de los procesos de trabajo durante la revolución industrial se naturalizó, se transformó en sentido común y en sinónimo de progreso social. Se supuso que la máquina y la lógica que emergían dominarían todos los campos del trabajo para el bienestar de la población y, en ello, la ciencia tenía un rol muy importante.

La teoría general de la administración (TGA) desde sus inicios a principios del siglo XX, quedó marcada por los conceptos anteriores. No es un dato menor que fuera el capitalismo casi el único que se interesara en el desarrollo de la TGA. Las ideas de productividad, eficacia, eficiencia, supervisión, control y calidad originadas en los modelos industriales fueron sustituyendo la libertad que brindaba el trabajo artesanal. Muchas décadas después, la revolución tecnológica reforzó esas limitaciones a través de la informática y la robótica al punto de prescindir del trabajador. Pero todo esto no puede ser extrapolable al proceso de trabajo médico y a la organización de salud (con el hospital como modelo paradigmático), donde se pueden reconocer dimensiones del trabajo más relacionadas con lo artesanal que con lo industrial y un diseño organizacional muy lejano de esa estructura piramidal presente en el imaginario social. 
¿Cómo es eso? Observemos el trabajo de un médico o de cualquier otro profesional de la salud y veremos que está dominado por lo artesanal, que detrás de la ilusión de la "objetividad científica" su práctica cotidiana se aproxima más a la del artesano que a la de la máquina. Por lo tanto, en términos de lógica industrial su trabajo aparece como caótico ya que es casi imposible de estandarizar y/o medir su productividad de manera cuantitativa, objetiva y regular, tanto así que no se puede predecir qué va a producir, cuánto va a producir, ni cuánto va a gastar en esa producción, ni que su acción sea correcta. Si prestamos atención al trabajo médico, no tardaremos en reconocer su carácter artesanal, de tal manera que profesionales de las mismas especialidades generan distintos diagnósticos y/o recomendaciones por cuestiones de intereses económicos, concepciones y/o conocimientos. De allí la multiplicidad de modelos de atención que conviven para abordar los mismos problemas. El modelo de trabajo industrial solo se puede observar en algunas áreas de diagnóstico y tratamiento donde las máquinas pudieron entrar y reemplazar el trabajo humano. Cuando el modelo industrial invade otras especialidades -por ejemplo 15 minutos cada consulta- lo hace a costa del vínculo de ese profesional con la comunidad, con la institución, con los equipos y/o con el paciente.

La proliferación de conocimientos al interior de las especialidades lleva a los profesionales de la salud a que cada día sepan más de menos; de allí la calificación que hiciera de los universitarios Ortega y Gasset: "los bárbaros modernos". Lo que antes requería de un profesional para ser realizado, hoy requiere de más profesionales, sin que ello asegure una mejor atención, ya que en general el aumento del número de profesionales va en detrimento de la calidad, como predica aquel viejo adagio: "Quien tiene un médico, tiene un médico, y quien tiene dos médicos, no tiene médico". La súper especialización no solo fragmenta el trabajo, sino también al paciente que queda en medio de distintas comunicaciones, que recibe sin un proceso de coordinación, de manera tal que termina siendo él su propio gestor, ya sea del malestar o de la enfermedad; comunicaciones que no pocas veces son contradictorias, o que conllevan críticas hacia otro de los profesionales intervinientes, ante la mirada desconcertada del paciente (nunca más apropiada la denominación). Esto se exacerba en los modelos privados que tercerizan servicios por donde el usuario transita pensando que está en una sola organización, cuando en realidad está en un «shopping», donde diferentes actores, con distintos intereses, pujan por vender sus servicios y/o incrementar sus ganancias aunque ello signifique dar menos prestaciones, (aunque sean necesarias) o poner en peligro la vida del paciente.

A nivel del diseño organizacional también se observa algo atípico para la TGA y que está determinado por las singularidades del proceso de trabajo que describimos. Las "organizaciones" de salud son totalmente diferentes a las demás organizaciones, por su complejidad, por el tipo de objeto con el cual trabajan-que es radicalmente diferente al de las organizaciones industriales- y por la especificidad de los conocimientos de sus trabajadores. Todo ello nos permite afirmar que son de las organizaciones más complejas que tiene la sociedad para dirigir. Fue Henry Mintzberg, con su descripción de la "Burocracia Profesional”, quién realizó un excelente retrato de la naturaleza de la organización hospitalaria, y es allí donde describe esos niveles de autonomía de la base de la organización que lo llevan a caracterizarlas como las organizaciones más democráticas de la sociedad. ¿Por qué? Porque a ese trabajador es muy difícil controlarlo tal como lo planteó y consiguió Taylor. Es un trabajador cuyo conocimiento del quehacer en el día a día, lo obtiene por afuera de su organización (revistas científicas, sociedades científicas y/o congresos), y muy rara vez de las órdenes de los niveles superiores. Ese conocimiento técnico se transforma en su principal poder y lo "inmuniza" ante los intentos de control, ya que su herramienta central de trabajo no son las manos o los pies, como el obrero industrial, sino la palabra que le da la libertad de producir de manera nómade -en cualquier lugar y en cualquier momento- y es 
a través de la cual expresa sus conocimientos de manera más o menos críptica, según corresponda o sea funcional a sus intereses. El producto de su trabajo, muchas veces, no es tangible, se consume mientras se produce. Es una organización que se basa principalmente en seres humanos, no solo como fuerza de trabajo, sino también como inteligencia, la cual define dominios, que muy pocas veces son compartidos por la conducción superior, creando en esos niveles superiores una gran dependencia al interior de la propia organización de salud. Esta característica es lo que permite la creación de espacios cerrados, de baja gobernabilidad para la conducción de más alto nivel. Las organizaciones de salud se basan en relaciones interpersonales, tanto a nivel de equipos como de los usuarios. Esto que es tan obvio, no es pensado y se le exige un comportamiento piramidal.

Esa imagen piramidal que en general se asocia como modelo para describir una organización, con el poder en el vértice y con una base sometida, controlada y explotada por la cúpula dirigente, está muy lejos de ser el modelo de las organizaciones de salud, para las cuales resulta más propicio graficarlas como pirámides invertidas. Estas discusiones, en general, están fuera de agen$\mathrm{da}$, pese a que la disponibilidad del conocimiento es de larga data: solo pensemos que Mintzberg publica el concepto de "Burocracia Profesional” en 1979.

Tampoco se puede desconocer el rol que tiene el "paciente" que, a diferencia del objeto industrial que se somete a la máquina, no solo habla, sino que se autoclasifica, interactúa, evalúa lo prescrito y decide de manera independiente y autónoma sobre calidad, pertinencia y tiempos de las indicaciones de los profesionales. Su rol es tan central que la antropología médica señala a la familia como el primer nivel de atención de salud.

Detrás de la apariencia de evidencias, algoritmos y guías clínicas se esconde una práctica sin conceptos - “sentido práctico" dirá Pierre Bourdieu- en la que se trata de montar un trabajo artesanal (lo real) en una línea fordista (lo imaginado), ignorando el alto poder generativo del lenguaje como parte central de la organización (lo simbólico). ¿La consecuencia? Una organización que se ve a sí misma y de manera constante a punto de estallar. La tensión que provoca ese trabajo artesanal y la pirámide invertida en la lógica tradicional de la teoría de las organizaciones lleva a pugnar por introducir maquinas, computadoras y hasta robots, a los que se suman los intentos de corregir esa “mutación” de la pirámide, flexibilizando las relaciones de empleo para volverla a "la normalidad" y que sea la cúpula la que comande y la base pierda esa autonomía. La privatización de los servicios de salud es la propuesta para solucionar la caracterización anterior, tanto del proceso de trabajo, como del diseño organizacional. Esta visión no solo es falsa sino que demuestra una profunda ignorancia acerca de las características del proceso de trabajo y las singularidades de las organizaciones de salud, en tanto diseño determinado por el proceso de trabajo.

Esas lógicas no quieren reconocer las dimensiones positivas del trabajo artesanal que permiten la construcción del vínculo entre trabajadores y usuarios y, por lo tanto, del cuidado del otro en tanto espacio de la micropolítica. Es ese proceso relacional el que tiene la potencialidad de construir un vínculo de afecto, confianza y respeto, que es la mejor cura para la violencia que apareció en las últimas décadas en los servicios de salud. Omitir la dimensión del vínculo lleva a la autovictimización del profesional, y a reducir la complejidad de la situación a "nuevas nosologías" como el "síndrome del médico agredido", o colocar la solución en la permanencia de la policía en los hospitales. Soluciones simples para problemas complejos indican la falta de pensamiento de las verdaderas “causas”.

Las tensiones que este escrito señala se encuentran en el título del Decimoquinto Congreso Internacional de Medicina Interna del Hospital de Clínicas de la Universidad de Buenos Aires: "Medicina: del Humanismo a la Ciencia y el Arte”. Puede visualizarse allí la tensión entre ciencia y humanismo, o mejor dicho la ciencia concebida como una fase superior del humanismo, pero que aun así no pueden dejar de reconocer el carácter del arte de la medicina (decir artesano hubiese resultado 
poco científico). Todo esto indica que las tensiones señaladas existen al interior del campo de la salud y que cada vez son más evidentes. Tensiones que no se resuelven con la privatización de los servicios de salud como se sostiene desde el pensamiento liberal que busca transformar un derecho en una mercancía, sino que nos obligan a pensar el campo de la salud desde nuevas miradas y conceptos que respeten sus singularidades y garanticen la salud como un derecho de las personas, asegurado y pro- tegido por el Estado. Las áreas sociales necesitan urgentemente desarrollar teorías para sus prácticas -que distan mucho de los modelos industriales-, de manera de ser garantes de la ejecución de esos derechos en la práctica, más allá de los discursos, logrando que la palabra se convierta en política y no quede limitada al papel. Hasta entonces no está mal recordar lo que afirmaba aquel gran médico español, Gregorio Marañón (1887-1960): "la mejor herramienta del médico es la silla”. 